\title{
EDITORIAL
}

\section{Evidence-Based Versus Myth-Based Treatment of Suspension Syndrome}

Keywords: rescue, harness hang syndrome, venous pooling, death on rope, orthostatic intolerance

The first known mention of deaths while on rope that had no obvious cause was in 1972 at the second international conference of mountain rescue doctors in Innsbruck, Austria. ${ }^{1}$ Trauma could not explain the deaths. Some climbers had died while suspended, and in one worrisome case, the victim died immediately after rescue. Some speakers attempted to explain the deaths and made recommendations for prevention. They recommended against placing a victim supine "abruptly" after rescue, although they did not define "abruptly." 2 The recommendations were buried in obscurity for 3 decades.

Twelve years later, in 1984, the medical commission of the French Federation of Speleology noted a number of cavers who died while on rope. ${ }^{3}$ These deaths had previously been attributed to hypothermia, but the time to death seemed too short. The commission studied the phenomenon by putting volunteers on rope and having them hang as if they were unconscious. Syncope sometimes occurred within minutes. The commission concluded that there was more to caver deaths on rope than hypothermia.

Suspension is not a single syndrome. There are case reports of an acute phase with syncope or death on rope, sometimes occurring minutes after the victim became passive. ${ }^{1,4}$ There are rare reports of death soon, sometimes only minutes, after rescue. ${ }^{1,3,5}$ There are also cases of subacute renal failure from rhabdomyolysis after suspension. ${ }^{1,6}$

In 2002, the Health and Safety Executive (HSE) of England created recommendations to protect workers on rope. ${ }^{7}$ They unearthed the 1972 recommendations and suggested that victims who experienced syncope while on rope not be placed lying flat for at least $30 \mathrm{~min}$ after rescue. The HSE also recommended that rescuers not remove the victim's climbing harness. Despite a lack of evidence, these recommendations became standard in the mountaineering, caving, rope access, and search and rescue communities. A single case of death immediately after rescue led to widespread speculation on the Internet regarding the cause of death. One theory involved rupture of the heart from blood returning to the central circulation from the periphery.

In 2009, the original HSE recommendations began to be questioned. ${ }^{4,8-10}$ The HSE then found that the previous recommendations lacked supporting evidence. ${ }^{9}$ The HSE suggested instead that suspension victims be treated no differently than patients with other types of syncope. ${ }^{9}$ The US Occupational Safety and Health Administration issued similar recommendations in 2011. ${ }^{11}$

A study published in this issue of Wilderness \& Environmental Medicine and a related study by the same group have brought more clarity to suspension syndrome. ${ }^{12,13}$ The authors examined the widespread belief that blood pools in the legs when an individual is passively suspended. These studies confirmed this hypothesis by using ultrasound to visualize the superficial femoral vein, which, despite its name, is a deep vein. Ultrasound showed distension of the superficial femoral vein while study participants were passively suspended; the vein returned to normal once the participants were lying down. In normal circumstances, muscle contractions in the legs squeeze blood upward, past 1-way valves, back to the heart. The studies also confirmed the widely held hypothesis that moving the legs could restore circulation of pooled blood. Ultrasound showed stasis of blood in the vein while participants were passively suspended, followed by rapid resumption of venous flow with movement. ${ }^{12,13}$ Although the true incidence of suspension syndrome is not known, it is rare. These studies, consistent with other studies, suggest that $30 \%$ of climbers and others suspended on rope are at risk. ${ }^{14}$

More importantly, the new studies debunk some persistent myths. One myth is that rapid venous return after lying a victim flat could overload the right side of the heart, causing immediate "rescue death." Echocardiography in these studies showed that the heart, which shrank owing to venous pooling, returned to its original size after rescue, without additional enlargement. The notion that fainting while suspended passively on rope was due to insufficient cardiac preload owing to sequestration of blood in the legs, possibly from a Bezold-Jarisch reflex (bradycardia, vasodilation, and hypotension due to stimulation of cardiac mechanoreceptors), is incorrect. Echocardiography confirmed that cardiac preload remained adequate. ${ }^{13}$ Instead, syncope resulting from suspension seems to be a neurally 
mediated phenomenon in which heart rate and blood pressure fall abruptly.

Another myth was that harness straps caused suspension syndrome by compressing the femoral arteries and veins. This led to terminology such as "harness pathology" and "harness hang syndrome" based on the false belief that the harness was at fault. This terminology suggested that either removing or leaving the harness should be important after rescue. It is now clear, based on ultrasound imagery of suspended volunteers, that the femoral vein and artery are not affected by a sit harness. Passive suspension is the problem, rather than compression of vessels by the harness. ${ }^{12}$ Harness management should not delay rescue or first aid.

Passive suspension should be taken seriously. There should be a plan for rescuing a victim who cannot selfrescue from suspension on rope. Rescuers should encourage conscious victims who are suspended and who cannot extricate themselves to keep moving their legs while awaiting rescue. Victims of syncope due to suspension should be placed flat immediately after extrication and should be treated in the same manner as any other victim of syncope.

The debacle of earlier recommendations for treatment of suspension syndrome is a demonstration of what can happen when recommendations are made without evidence. This is especially the case for deviations from standard recommendations without positive evidence. Expert opinion can be wrong. This episode also demonstrated how those relying on the Internet and other nonpeer-reviewed statements can too easily spread incorrect, dangerous information. ${ }^{10}$ Skepticism is always warranted. The current practice of publishing evidencebased guidelines with stated levels of evidence for individual recommendations is a tremendous step forward in preventing future widespread dissemination of dangerous medical recommendations.

Author Contributions: RBM wrote the first draft. RBM and $\mathrm{KZ}$ revised the manuscript.

Financial/Material Support: None.

Disclosures: None.

Roger B. Mortimer, MD

Department of Family Medicine, UCSF Fresno Medical Education Program, Fresno, California; International Commission for Mountain Emergency Medicine (ICARMEDCOM), Zürich, Switzerland

Ken Zafren, MD

Department of Emergency Medicine, Alaska Native Medical Center, Anchorage, Alaska; Department of Emergency Medicine, Stanford University Medical Center, Palo Alto, California
Corresponding author: Roger B. Mortimer, MD, UCSF-Fresno Medical Education Program, Department of Family Medicine, 155 N. Fresno Street, Fresno, CA 937012302 Email address: rmortimer@fresno.ucsf.edu

\section{References}

1. Flora G, Holzl HR. Fatal and non-fatal accidents involving falls into the rope. Paper presented at: 2nd International Conference of Mountain Rescue Doctors; November 18, 1972; Innsbruck, Austria; 1972:5-11.

2. Flora G, Margreiter R, Dittrich P, Stuhlinger W. Hanging tests-Conclusions for the mountaineer. Paper presented at: 2nd International Conference of Mountain Rescue Doctors, November 18, 1972; Innsbruck, Austria; 1972:49-52.

3. Bariod J. Sensibilisation a la Pathologie Induite par l'Utilisation du Harnais. Helecine, Belgium: European Conference of Speleology; 1992.

4. Mortimer RB. Risks and management of prolonged suspension in an Alpine harness. Wilderness Environ Med. 2011;22(1):77-86.

5. Knutson S. American caving accidents 1993. NSS News. 1994;52(12, part 2):388-9.

6. Wharton DR, Mortimer RB. Rhabdomyolysis after prolonged suspension in a cave. Wilderness Environ Med. 2011;22(1): $52-3$.

7. Seddon P. Harness Suspension: Review and Evaluation of Existing Information. Colgate, Norwich: Health and Safety Executive; 2002.

8. Pasquier M, Yersin B, Vallotton L, Carron PN. Clinical update: Suspension trauma. Wilderness Environ Med. 2011;22(2):167-71.

9. Adisesh A, Robinson L, Codling A, Harris-Roberts J, Lee C, Porter K. Evidence-Based Review of the Current Guidance on First Aid Measures for Suspension Trauma. Colegate, Norwich: UK Health and Safety Executive; 2009.

10. Thomassen O, Skaiaa SC, Brattebo G, Heltne JK, Dahlberg T, Sunde GA. Does the horizontal position increase risk of rescue death following suspenion trauma? Emerg Med J. 2009;26(12):896-8.

11. Occupational Safety and Health Administration. Suspension trauma/orthostatic intolerance. Available at: https://www.osha. gov/dts/shib/shib032404.html. Accessed February 7, 2020.

12. Rauch S, Schenk K, Gatterer H, Erckert M, Oberhuber L, Bliemsrieder B, et al. Venous pooling in suspension syndrome assessed with ultrasound. Wilderness Environ Med. 2020;31(2):204-8.

13. Rauch S, Schenk K, Strapazzon G, Cappello T, Gatterer H, Palma M, et al. Suspension syndrome: a potentially fatal vagally mediated circulatory collapse-an experimental randomized crossover trial. Eur J Appl Physiol. 2019;119(6): 1353-65.

14. Madsen P, Svendsen LB, Jorgensen LG, Matzen S, Jansen E, Secher NH. Tolerance to head-up tilt and suspension with elevated legs. Aviat Space Environ Med. 1998;69(8):781-4. 